RELACult - Revista Latino-Americana de Estudos em Cultura e Sociedade

\title{
Dicionário das crianças: uma possibilidade de significados e representações de gênero no universo infantil ${ }^{1}$
}

\author{
Diccionario de los Niños: una possibilidad de significados y \\ representaciones de género en el universo infantil
Children dictionary: a chance of meanings and representations of gender in children's universe

Tatiani Müller Kohls ${ }^{2}$

Vagner de Souza Vargas ${ }^{3}$

Denise Marcos Bussoletti ${ }^{4}$

\begin{abstract}
Resumo
Pensar as representações de gênero no universo infantil, dentro do espaço escolar, também significa refletir sobre normas impostas, assim como sobre as distinções entre crianças que, desde à pré-escola, já são diferenciadas entre meninas e meninos. O objetivo deste trabalho é apresentar uma proposta de pesquisa, relacionando-a com os princípios de Pedagogia da Fronteira e Estética da Ginga que vêm sendo desenvolvidos a partir dos trabalhos do Núcleo de Artes, Linguagens e Subjetividades, da Universidade Federal de Pelotas. A partir dessas evidenciações, talvez, teremos a oportunidade de contextualizar, propor discussões e reflexões sobre como as construções/normatizações de gênero são formadas durante a infância para, então, quem sabe, propormos atividades questionadoras de tais observações.
\end{abstract}

Palavras-Chave: Educação, Estética da Ginga, Gênero, Pedagogia da Fronteira, Diversidade.

\section{Resumen}

Pensar en representaciones de género en el universo infantil dentro del ambiente escolar también significa reflexionar sobre las normas impuestas, así como sobre las distinciones entre los niños de preescolar, que ya se diferencian entre niños y niñas. El objetivo de este trabajo es presentar una propuesta de investigación, relacionándolo con los principios de la Pedagogía de la Frontera y Estética de Ginga que se han desarrollado a partir del trabajo del Núcleo de Artes, Lenguajes y Subjetividades, de la Universidad Federal de Pelotas. A partir de estas revelaciones, tal vez, tener la oportunidad de contextualizar y proponer debates y reflexiones sobre las construciones/normatizaciones de género se forman durante la infancia para, entonces tal vez proponer actividades que cuestionan tales observaciones.

Palabras claves: Educación, Estética de Ginga, Género, Pedagogía de la Frontera, Diversidad.

\footnotetext{
${ }^{1}$ Este trabalho faz parte da dissertação de mestrado, em andamento, de Tatiani Müller Kohls, no Curso de Mestrado em Educação, do Programa de Pós-graduação em Educação (PPGE), da Universidade Federal de Pelotas (UFPEL). ${ }^{2}$ Mestre em Antropologia, Programa de Pós-Graduação em Antropologia, Universidade Federal de Pelotas (UFPEL); Mestranda em Educação, Programa de Pós-Graduação em Educação, Universidade Federal de Pelotas (UFPEL). E-mail: tatianimuller@gmail.com

${ }^{3}$ Doutorando em Educação, Programa de Pós-Graduação em Educação, Universidade Federal de Pelotas, Bolsista CAPES, Ator, Licenciado em Teatro. E-mail: vagnervarg@gmail.com

${ }^{4}$ Doutora em Psicologia, Professora do Programa de Pós-Graduação em Educação. Faculdade de Educação. Universidade Federal de Pelotas. E-mail: denisebussoletti@gmail.com
} 


\begin{abstract}
Think representations of gender in children's universe within the school environment also means reflecting on imposed standards, as well as on the distinctions between children from the preschool, they are already differentiated between girls and boys. The aim of this paper is to present a research proposal, relating it to the principles of Pedagogy of the Border and Aesthetics of Ginga that have been developed from the work of the Arts Center, Languages and subjectivities, the Federal University of Pelotas. From these disclosures, perhaps, have the opportunity to contextualize propose discussions and reflections on the buildings/gender norms are formed during the childhood, then perhaps proposing questioning activities of such observations.
\end{abstract}

Keywords: Education, Aesthetics Ginga, Gender, Border Pedagogy, Diversity.

\title{
1. Introdução
}

Pensar as representações de gênero no universo infantil, dentro do espaço escolar, também significa refletir sobre normas impostas, assim como sobre as distinções - também impostas - entre crianças que, desde a pré-escola, já são diferenciadas entre meninas e meninos. Considerar esses fatos também implica em pensar sobre os elementos críticos encontrados na cultura infantil e o que ainda podemos apreender com as crianças sobre suas representações.

Evidenciar outras identidades no espaço educacional requer uma busca à educação voltada para a diversidade cultural e social, adentrando no espaço real e imagético das experiências infantis, buscando, nesse universo de possibilidades, desvendar, não só como as crianças se percebem, mas também como representam esse contexto e as próprias situações que vivem e estão expostas diariamente. Baseando-se na ideia do livro "Casa das Estrelas: o universo contado pelas crianças", do professor colombiano Javier Naranjo (2013), no qual ele apresenta a maneira como as crianças percebem e compreendem o mundo, buscamos inspiração para o projeto "Dicionário das crianças: Uma possibilidade de significados e representações de gênero no universo infantil’". Durante suas aulas, Naranjo (2013) solicitava às crianças que escrevessem o significado de determinadas palavras e, posteriormente, transformou essas atividades em um livro, um dicionário, apresentando a visão de mundo que elas tinham na infância.

A poética e a visão crítica encontradas na infância por Naranjo (2013) podem ser comparadas ao que Bussoletti \& Schneider (2012, p. 301) referem ao dizer que "a infância se estabelece assim, aos nossos sentidos, como um enigma constante e renovado. A infância acaba por questionar nossas certezas, tanto as certezas de mundo, como as que consideramos como próprias". Dessa forma, esse projeto se propõe a estimular a reflexão sobre a cultura da infância, a partir das palavras de crianças permeando a imaginação, o lúdico e o real. 
A partir do livro e da poética proposta por Naranjo (2013), desenvolvemos algumas questões iniciais a este projeto, tais como: o que ainda podemos apreender com as crianças, sobre suas maneiras de ver o mundo, sobre sua sensibilidade, seus valores, sua estética e suas representações? Como podemos nos aprofundar no mundo imagético e nos aproximar desse universo com suas diversas possibilidades? Como pensar em um processo de educação voltado para a diversidade cultural e social, buscando na cultura infantil premissas de significações acerca da forma como as crianças percebem o mundo?

A partir desses questionamentos, vieram inquietações que nos instigaram a expandir o campo reflexivo também para as relações de gênero nesse contexto. Mas por que pensar sobre educação e as representações infantis sobre gênero? Acreditamos que, em face de tantos debates atuais acerca de questões relacionadas ao desenvolvimento de trabalhos sobre gênero na escola, devemos também voltar nosso olhar para as crianças e, através de suas representações, tentar compreender como elas percebem essas relações, conceitos e como elas próprias se percebem no mundo enquanto meninas e meninos.

Pensar sobre o nosso processo de formação no espaço educacional implica em pensar também sobre nossa formação/construção como mulheres e homens. Isso também significa pensar e questionar as normas corporais, reguladas, sugeridas ou condenadas nesse universo (LOURO, 2010). Mas quais são essas normas? De acordo com Louro (2010, p.11), “os corpos ganham sentido socialmente. A inscrição dos gêneros - feminino ou masculino - nos corpos é feita, sempre, no contexto de uma determinada cultura e, portanto, com as marcas dessa cultura". Essas normas seriam aquilo que entendemos como comportamentos tidos como "naturais", que produzimos e reproduzimos na sociedade e principalmente na escola. O objetivo deste trabalho é apresentar a proposta de pesquisa acima exposta, relacionando-a com os princípios de Pedagogia da Fronteira e Estética da Ginga que vêm sendo desenvolvidos a partir dos trabalhos do Núcleo de Artes, Linguagens e Subjetividades (NALS), na Faculdade de Educação (FaE), da Universidade Federal de Pelotas (UFPEL).

\section{O NALS, suas pedagogias e estéticas}

Ao longo dos anos, o NALS vem trabalhando com o intuito de propor atividades que levem reflexões sobre diversidade, fronteira, cultura, identidade, direitos humanos e outras pedagogias à comunidade local (ALVES, 2012; KRUGER, 2012; VARGAS; BUSSOLETTI, 2012; 2015; BUSSOLETTI; VARGAS, 2012; 2013a; 2013b; 2014a; 2014b; BUSSOLETTI, 
VARGAS; BAIRROS, 2013; BUSSOLETTI; VARGAS; RIBEIRO, 2014; BUSSOLETTI; VARGAS; KRUGER, 2014; BUSSOLETTI, 2016). Nossas atividades dialogam com alguns conceitos propostos por Arroyo (2014), Santos (1999), Santos \& Meneses (2010), dentre outros.

Somos levados a crer que urge consolidar o que pode ser compreendido como "pedagogia da fronteira". Uma pedagogia que paute o seu compromisso pelo restabelecimento crítico da formação pedagógica, mantendo o espaço para as perguntas mais do que para as respostas conceituais e acabadas, suportando a experiência radical da diversidade e da diferença, aproximando e tornando presentes as linhas que por vezes separam e tornam, desafortunadamente, as fronteiras intransponíveis (BUSSOLETTI; VARGAS, 2013a; 2014a).

Por meio do que apresentamos até aqui é que compreendemos a possibilidade de tratamento e apreensão de um modelo de subjetividade que resiste na condição espaço-temporal de fronteira. A compreensão desse processo que contribui e acaba por revelar estéticas emergentes oriundas da mestiçagem e dos cenários nos quais a interculturalidade conduz, configurando aquilo que defendemos também como sendo uma "Estética da Ginga" (BUSSOLETTI; VARGAS, 2013a; 2014a).

A Estética da Ginga, defendida em nossos trabalhos, tem suas bases no que foi referido por Jacques (2003), sobre o trabalho dos Parangolés, de Hélio Oiticica (1939-1980) e a sua proposta de "anti-arte". Refletindo sobre as possibilidades de mudanças e ações ativas sobre determinadas produções artísticas, conferindo ao espectador não mais o papel de agente passivo ante aos fatos que estão sendo criados, expostos ou apresentados, Oiticica propunha que o espectador influi, interage, modifica, constrói, participa, agrega e também faz parte do processo de criação da obra de arte (FAVARETTO, 2000). Ampliando essas percepções de Oiticica sobre o campo das artes, chegamos as nossas atividades com o NALS considerando que, independentemente da abordagem que estamos realizando na comunidade local naquele instante, os indivíduos envolvidos possuem as mesmas potencialidades conforme Oiticica referia sobre a relação entre participador e obra de arte.

Mesmo falando sobre o fazer artístico, Hélio Oiticica nos fornece um princípio que pode ser expandido para quaisquer áreas do conhecimento, uma vez que sua proposta conceitual retira os indivíduos da passividade e ostracismo em face dos acontecimentos a sua volta e salienta que todos podemos interagir ativamente na construção da realidade que nos cerca, assim como do que nossa sociedade produz. Oiticica nos permite refletir e conceber que todos cidadãos podem ser capazes de produzir trabalhos que sejam importantes e toquem de certa 
maneira a sociedade. Nesse momento, podemos trazer esses princípios a nossas ações, com o intuito de propormos atividades que levem essas reflexões a comunidades que costumam estar apartadas da percepção dos seus direitos, possibilidades de contribuição e mudanças na sociedade (BUSSOLETTI; VARGAS, 2013a; 2014a).

Além disso, a Estética da Ginga também nos propõe um conceito ético e estético onde a diversão, os sentimentos de prazer e felicidade surgem a partir das trocas, intercâmbios, trânsitos e interações entre os diversos tipos de informações, experiências, características, matizes e possíveis fronteiras que existam entre os diferentes grupos sociais, manifestando-se e desenvolvendo como na cadência de um samba. A metáfora de ginga e samba são aqui utilizadas para ilustrarem e/ou indicarem um tipo de movimento que transita, que vai e volta, não se fixando, não ocorrendo de maneira unidirecional, mas ressaltando que as comunicações, trocas de informações, conhecimentos, experiências e saberes se dão de maneira constante, em fluxo e ativamente, em uma sociedade que esteja aberta para essa possibilidade. Outra característica utilizada para empregar o conceito de Estética da Ginga, surge do fato dessas manifestações populares serem oriundas de uma mestiçagem, de características de um povo que agrega em si a diversidade de características da sociedade, fazendo com que suas peculiaridades do somatório de cruzamentos e intercâmbios de características se manifestem como um aspecto positivo de sua diversidade e, justamente, essa diversidade polissêmica confere o seu empoderamento e felicidade, desde que essa sociedade consiga perceber a qualidade e a importância de sua diversidade (BUSSOLETTI; VARGAS, 2013a; 2014a).

\section{Dicionário das crianças: uma possibilidade de significados e representações de gênero no universo infantil}

Tendo-se as crianças como produtos e produtoras de nossa cultura e da sociedade, e ainda pensando sobre os elementos e significações do "mundo adulto" apropriado pelas crianças, voltamo-nos a pensar sobre as representações de gênero no universo infantil. Ao pensar sobre essas representações, Bíscaro (2009, p. 06) discorre sobre a construção das identidades de gênero na educação infantil, a partir das "discriminações causadas por uma educação sexista, onde se atribuem às meninas a sensibilidade, fragilidade e aos meninos a brutalidade e força". A escola, o espaço de educação em si, nos constrói como sujeitos femininos ou masculinos, nos atribuindo "marcas" e educando nosso corpo de acordo com as normas impostas, tidas como naturais. Sobre esse corpo marcado e padronizado pela sociedade, 
Louro (2010, p. 11) salienta que é "através de processos culturais, definimos o que é - ou não - natural; produzimos e transformamos a natureza e a biologia e, consequentemente, as tornamos históricas" (LOURO, 2010, p. 11). Assim, dentro do cenário atual, frente às transformações sociais e culturais, no que diz respeito às questões de gênero e sexualidade, Louro (2010, p. 10) aponta que "uniões afetivas e sexuais estáveis entre sujeitos do mesmo sexo se tornam crescentemente visíveis e rotineiras; arranjos familiares se multiplicam e se modificam", sendo que essas transformações perpassam também pelo universo educacional e pela cultura infantil, afetando "sem dúvida, as formas de viver e de construir identidades de gênero e sexuais".

Refletir sobre gênero e sexualidade a partir das representações infantis é também problematizar sobre essas "marcas" corporais que imprimimos nas crianças e em suas identidades sociais, pois a discriminação e a educação sexista, parte de nós, como educadores ou não, tendo-se como base aquilo que empregamos como "natural" aos corpos, que ganham sentido socialmente no contexto de uma determinada cultura (LOURO, 2010).

$\mathrm{Na}$ perspectiva de tornar compreensíveis as representações infantis, buscando suas representações nas questões de gênero, pensamos que imergir nesse universo, interagir com as crianças, trata-se também de um envolvimento subjetivo e sensível e de experimentação. Nesse sentido, através da experiência do sensível e do subjetivo, buscaremos captar os valores sociais e simbólicos na cultura infantil, a fim de melhor descrever suas representações e significações.

A construção do dicionário das crianças foi pensada a partir de oficinas de contação de histórias, buscando inicialmente uma aproximação e inserção na cultura infantil. Através dessas narrativas, propomos também a construção de personagens e a problematização dos estereótipos da infância, apresentando o contexto ao qual a história se passa a partir da visão cultural e social da criança. A busca pelas palavras que irão compor o "dicionário" e a visão que as crianças possuem sobre as questões de gênero se dará a partir dessa troca, dessas histórias, narrativas e diálogos que iremos propor durante as oficinas, evidenciando a visão e a própria experiência das crianças como meninas e meninos.

Mas como coletar essas palavras? Além das observações, da interação, a proposta é também pedir que as crianças escrevam o significado das palavras que permearão a discussão, como o que é criança, o que é ser menina, o que é ser menino e a partir daí, buscar problematizar essas representações. A análise e o tratamento das representações pretendem seguir as reflexões em torno da abordagem da escrita de pesquisa na infância, tal como é abordada por Bussoletti 
(2007), como um "exercício de alteridade", através da infầncia e buscando nesse "Outro", que são as crianças, novas possibilidades de significações ou ressignificações da cultura.

\section{Considerações finais}

Tendo em vista as propostas e atividades desenvolvidas pelo NALS, o presente projeto, relacionado à investigação dos conceitos de gênero presentes no universo infantil, vem ao encontro dos princípios de pedagogia da fronteira e estética da ginga, uma vez que, possivelmente, estaremos adentrando em um espaço que se reivindica necessário de observação ante as normatizações já impostas pela sociedade desde os primeiros anos de vida. Além disso, a partir dessas evidenciações, talvez, teremos a oportunidade de contextualizar e propor discussões e reflexões sobre como as construções/normatizações de gênero são formadas durante a infância para, então, quem sabe, propormos atividades questionadoras de tais observações.

Evidenciamos, ainda, a importância de se buscar uma educação voltada para a diversidade cultural e social, além de adentrar no espaço real e imagético das experiências infantis, buscando nesse universo de possibilidades, não só de acessar o universo das crianças e suas representações, mas também como representam esse universo e as próprias situações que vivem e a que estão expostas. Tomamos a infância como um momento de reflexividade, no sentido de crítica aos modelos como a pesquisa em educação vem se instituindo e da tarefa urgente de refletir acerca do que as crianças têm a nos dizer.

\section{Referências}

ALVES, Joice do Prado; MELLO, Lawrence Estivalet; BUSSOLETTI, Denise Marcos. Diversidade Sexual: Diálogos e Práticas na Universidade. Expressa Extensão. Edição Especial, Dezembro de 2012; 25-42, 2012.

ARROYO, Miguel G. Outros Sujeitos, Outras Pedagogias. Petrópolis/RJ: Vozes, 2014.

BÍSCARO, Claudia Regina Renda. A construção das identidades de gênero na educação infantil. Campo Grande, 2009. 138 p. Dissertação (Mestrado) Universidade Católica Dom Bosco.

BUSSOLETTI, Denise Marcos; VARGAS, Vagner. Leituras em Dramaturgia Teatral para a Diversidade. Pelotas/RS: Editora e Gráfica Universitária UFPEL, 2012. 
Art and aesthetics of ginga: Boundary for the future in the in-between places of diversity. Global Journal of Human Social Science. Arts \& Humanities. v. 13, issue 04, pp. 01-09, 2013a.

22, 2013b.

Outras fronteiras em extensão. Revista Expressa Extensão, v. 18, n. 02, p.05-

Por entre fronteiras de uma pedagogia que pauta a educação pelas artes gingando saberes e práticas populares. Revista Extraprensa, v.01, n. 14, p. 41-48, 2014a.

History tellers: The Griots keeping popular narratives alive. Portuguese Studies Review, v. 22, n. 02, p. 175-192, 2014 b.

BUSSOLETTI, Denise Marcos. Infâncias Monotônicas - uma rapsódia da Esperança - Estudo psicossocial cultural crítico sobre as representações do outro na escrita de pesquisa. Porto Alegre, 2007. Tese (Doutorado em Psicologia) - Pontifícia Universidade Católica do Rio Grande do Sul.

BUSSOLETTI, Denise Marcos; VARGAS, Vagner; BAIRROS, Mariângela. Leituras em dramaturgia teatral para a diversidade. Volume II. Pelotas/RS. Editora e Gráfica Universitária UFPEL, 2013.

BUSSOLETTI, Denise Marcos; VARGAS, Vagner de Souza; RIBEIRO, Cristiano Guedes. Narrativas populares: o griô e a arte de contar histórias. Cadernos de Pesquisa, v. 21, n.1, p. 1$14,2014$.

BUSSOLETTI, Denise Marcos, VARGAS, Vagner de Souza; KRÜGER, Luana de Carvalho. The daily masks and socially sensitive identity: an ethical and aesthetical proposal for education in Brazil. Journal of Art for Life, 6(1):1-8, 2014.

BUSSOLETTI, Denise Marcos; DUARTE, Krischna Silveira; VARGAS, Vagner de Souza; NOGUEIRA, Gabriel Nogueira. Enseño de teatro para personas con Síndrome Down. Revista Hispanista, v. 27, n. 64, p. 01-10, 2016. Disponível em:

$<$ http://www.hispanista.com.br/artigos\%20autores\%20e\%20pdfs/artigo517esp.htm>. Acesso em 20 ago 2016.

BUSSOLETTI, Denise Marcos; SCHNEIDER, Daniela da Cruz. Infâncias e caixas: Pandora Esperança. Revista Contrapontos, Itajaí, SC., v. 12, n. 3, mar. 2012. ISSN 1984-7114. Disponível em: <http://www6.univali.br/seer/index.php/rc/article/view/2262/2380>. Acesso em 01 nov. 2015.

FAVARETTO, Celso. A Invenção de Hélio Oiticica. 2. ed. rev. São Paulo: Editora da Universidade de São Paulo, 2000.

JACQUES, Paola. Estética da Ginga: a arquitetura das favelas através da obra de Hélio Oiticica. Rio de Janeiro: Casa da Palavra, 2003.

KRUGER, Luana; BUSSOLETTI, Denise Marcos; SCHNEIDER, Daniela; PINHEIRO, Cristiano. Jogo de máscaras: as máscaras cotidianas e a educação. Expressa Extensão. n. 2, p. 25-42, 2012. 
LOURO, Guacira Lopes. Pedagogias da Sexualidade. In: LOURO, Guacira Lopes. (org.). O corpo educado - pedagogias da sexualidade. 3 ed. Belo Horizonte: Autêntica Editora, 2010.

NARANJO, Javier. Casa das estrelas: o universo contado pelas crianças. Rio de Janeiro: Foz Editora, 2013.

SANTOS, Boaventura de Souza. Pela mão de Alice - o social e o político na pósmodernidade. Porto/Portugal: Afrontamento, 1999.

SANTOS, Boaventura de Souza; MENESES, Maria Paula. Epistemologias do sul. São Paulo/SP: Cortez, 2010.

VARGAS, Vagner; BUSSOLETTI, Denise Marcos. Teatro sem fronteiras. Expressa Extensão. Edição Especial, Dezembro de 2012, p. 43-57, 2012. . Theatre, gender diversity and border pedagogy. Revista Diálogos

latinoamericanos, n. 24, p. 134-144, 2015. 